\title{
Can Physiology Help Us to Combat Late Blight in Potato?
}

\author{
Paul C. Struik
}

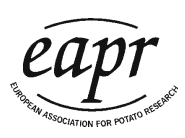

Received: 20 August 2010 /Accepted: 24 September 2010 /

Published online: 16 October 2010

(C) The Author(s) 2010. This article is published with open access at Springerlink.com

\begin{abstract}
Late blight is a devastating disease in potato production world-wide. Breeding for resistance is complex because of the versatile and aggressive population of Phytophthora infestans, which overcomes any new genetic source of resistance very rapidly. There are reliable fungicides available to control the disease, but chemical control is costly and harmful to the environment. There are no cultural practices reducing the infestation, which are reliable enough to cope with the disease in a non-chemical way. Given the close link between the physiological condition of the crop and its resistance to late blight, this paper addresses the question whether crop physiology can help to combat the disease. Although there are possibilities to (partly) escape to the late blight by advancing the crop cycle or the tuber bulking, it is concluded that crop physiology can do little to reliably reduce the susceptibility to late blight. Breeding for resistance remains the best option.
\end{abstract}

Keywords Canopy structure $\cdot$ Late blight $\cdot$ Leaf position · Maturity type $\cdot$ Phytophthora infestans $\cdot$ Potato · Resistance $\cdot$ Seed quality $\cdot$ Solanum tuberosum . Tuberization

\section{Introduction}

Potato late blight is caused by the oomycete Phytophthora infestans Mont. (de Bary). It did not come to Europe together with the potato (Solanum tuberosum L.) crop itself, but first occurred in Europe in the 1840s (Haverkort et al. 2009). It then led to the devastating Great Irish Potato Famine and to food crises on the European

This paper is based on: Struik PC (2010) Can physiology help us to combat late blight in potato? In: Çalişkan $\mathrm{ME}$ and Arslanoğlu F (ed), Potato AgroPhysiology, Proceedings of the International Symposium on Agronomy and Physiology of Potato, 20-24 September 2010, Nevșehīr, Turkey. pp. 19-27

P. C. Struik $(\bowtie)$

Centre for Crop Systems Analysis, Wageningen University, Droevendaalsesteeg 1, 6708 PB

Wageningen, The Netherlands

e-mail: paul.struik@wur.nl 
mainland as well. Potato late blight has not gone away ever since. It still is a major threat to potato production despite the following:

1. enormous efforts of breeders to create new varieties with improved resistance (either by including new $R$ genes, by pyramiding existing $R$ genes or by creating race-non-specific resistance) (Goverse and Struik 2009; Haverkort et al. 2009);

2. efforts of plant pathologists to identify the weak spots of the pathogen (Goverse and Struik 2009);

3. efforts of fungicide producers in designing new and more environmentally friendly crop protectants;

4. efforts by agronomists trying to grow more robust crops (Lammerts van Bueren et al. 2008); and

5. efforts by other scientists who might be able to contribute combating strategies through innovations (Struik 2006). Innovative approaches are, for example, creating diverse stands as a useful strategy in organic potato production (Finck et al. 2007), where mixtures of tubers might be valued by fresh potato consumers.

This paper is about the question: can crop physiologists help?

\section{The Late Blight Problem Has Worsened}

Late blight is particularly a problem in countries in northern Europe where the climate is relatively wet and cool. End users (especially processors) dictate the quality characteristics of potato tubers, but often also the agronomic crop traits that are desired. Such traits (e.g., an early maturity type) are difficult to combine with resistance to late blight, and the pressure to combine such contrasting traits by breeding is not large given the availability of effective, relatively cheap, chemical means to control late blight in conventional agriculture (i.e. fungicides). Despite major efforts to replace, for example, the susceptible cultivar Bintje, in many European and American potato growing areas late blight susceptible cultivars are still dominant. This continuous use of susceptible cultivars has been associated with an increase in the fitness of the late blight population and by a strong increase in the adaptive power of that population by the introduction of new strains of both the A1 and A2 mating types.

\section{The Late Blight Problem Is Threatening Organic Potato Production}

In organic potato production, despite much research, there are no means available to control late blight, except for applying copper-based fungicides, which is allowed under organic standards in certain countries but not in other ones. The only other control mechanism is killing the vine as soon as the leaf canopy becomes affected, a measure which might only be necessary on the longer term to avoid infestation of tubers, but which is promptly required anyway to avoid spread of inoculum to neighbouring (either organic or conventional) fields. Consequently, average potato 
yields in organic farming are low and variable, as they strongly depend on the timing and severity of late blight attacks (i.e. on date of haulm killing) (Lammerts van Bueren et al. 2008). Given this situation, the only feasible option in organic production is to delay the infection or to slow down the initial build-up of the epidemic. Once there is a certain level of leaf damage ( $7 \%$ in the Netherlands; Lammerts van Bueren et al. 2008), the crop needs to be killed mechanically by chopping or physically by burning the haulm, and measures to further delay the epidemic beyond the infection level of $7 \%$ are useless. By far the best option to realize a delay and slowing down of the epidemics in organic potato production is growing resistant cultivars.

\section{Breeding Seems the Only Option but Takes Time}

For the organic potato sector, breeding for resistant cultivars is the only route for combating late blight. In an extended trial with 281 cultivars under low-input conditions, only 36 cultivars yielded $30 \mathrm{Mg} / \mathrm{ha}$ regardless of late blight infection. Under Dutch conditions, this yield level is considered a minimum for economically sound, organic potato production. However, most of these 36 cultivars did not meet the standards for dry matter concentration, cooking quality, or/and frying quality (Lammerts van Bueren et al. 2008).

The level of resistance against late blight present in the cultivars which are currently commonly grown in Dutch organic agriculture is not sufficient to consistently produce that minimum yield level. There is a need to combine late blight resistance with earliness, a complex assignment as there seems to be genetic and physiological linkages between foliage maturity type and late blight resistance in the sense that early foliage maturity is usually associated with susceptibility (Visker et al. 2003a, 2004, 2005). Earliness is required to guarantee at least some yield when the late blight epidemic is early.

\section{Agronomy Does Not Help Much in Organic Potato Production}

Taking the lack of resistant varieties into account, research on a tool box for delaying the infection and slowing down the epidemic in organic potato production has been extensive. Strategies investigated included developing cultural practices, treating seed tubers to advance the crop and growing early and/or resistant varieties. Growing potato in association with another crop in strip cropping, intercropping or mixed cropping might have some effect in slowing down the epidemic of late blight (cf. Phillips et al. 2005; Finckh et al. 2006; Pilet et al. 2006; Bouws and Finckh 2008), but this needs more testing and seems complicated. Cultural practices changing crop structure and thus microclimate (especially in the lower leaf layers) are not effective and reliable enough to slow down the epidemic in its early phases (Bouws and Finckh 2008). The most effective measure seems to be advancing tuber set and tuber bulking (Hospers-Brands et al. 2005; Finckh et al. 2006; HospersBrands et al. 2008; Tiemens-Hulscher et al. 2007), and this is where crop physiology comes in. 


\section{Possible Crop Physiological Strategies to Cope with Biotic Stress}

A crop can develop several crop physiological strategies to cope with biotic stresses. These include:

1. escape, by completing the entire crop cycle before the stress becomes too harmful;

2. resistance, i.e. reducing the impact of the stress by avoiding or impeding the infection;

3. tolerance, by reducing the negative effects of a pathogen but allowing it to infest the plant (to some extent); and

4. recovery, by creating a properly functioning crop as soon as possible after the pathogen has been suppressed or controlled.

When a late blight epidemic hits a potato crop, there are three direct negative impacts:

1. The oomycete affects the foliage thus reducing the leaf area and thereby the crop's capacity to produce assimilates necessary for growth and maintenance of the haulm and for tuber bulking. This effect is more or less proportional to the level of loss of leaf area. If this would be the only negative effect, a certain level of late blight would be acceptable, also for organic potato crops.

2. The tubers might be directly infested. This effect is unacceptable, because this infestation reduces saleable tuber yield, but also since infected tubers can be an important source of inoculum for healthy tubers during storage. However, in many cultivars the tuber resistance to late blight is stronger than the foliage resistance thus providing a bit extra time after foliage infestation.

3. An infested crop becomes a source of inoculum. This is unacceptable especially in areas with a high proportion of the area cropped with potato and the more so if a high proportion of those crops are not protected because they are organic.

For these reasons, coping strategies for late blight stress can only include escape and resistance.

\section{Coping Strategies Specified}

In order to specify the possible role of crop physiology in the combat against late blight, we need to define the strategies escape and resistance in more detail.

Escape is possible in the following ways:

1. By advancing the entire crop cycle so that the crop is more mature when late blight strikes;

2. By accelerating the early canopy growth without advancing tuber bulking;

3. By advancing tuber bulking, without advancing canopy development, so that the tuber yield is higher when late blight strikes;

4. By accelerating tuber bulking, without advancing it.

The crop physiology-based resistance strategy is possible by:

1. Strengthening the race-non-specific foliage resistance; this is related to the behaviour of the crop, especially its foliage maturity type. It can result in a delay of initial infestation and a slower initial development of the epidemic until the 
epidemic has reached the level at which control or haulm killing becomes inevitable;

2. Influencing the micro-environment around the most sensitive plant parts (i.e. the basal leaves); this will also inhibit first infestation or slow down the development of the epidemic.

These aspects will be discussed below.

\section{Escape by Advancing the Entire Crop Cycle}

If conditions at planting time permit, early planting will in general be favourable to give the crop the earliest possible start. Advancing the crop can also be reached to some extent by planting larger seed tubers, but this effect depends on the combined effect of seed tuber size on the number of sprouts per tuber, the number of stems per sprout and the vigour of the individual stems from planting until they become autotrophic (Struik and Wiersema 1999). The number of stems per unit of seed weight will be crucial for the timing of tuber set, the rate of tuber bulking, the final number of harvestable tubers and their weight distribution.

Advancing the entire crop cycle obviously will change the conditions the crop experiences during the critical stages such as the period from planting until emergence, the period from emergence until stolon formation, the period from stolonization until tuberization, the period from emergence until full canopy cover and the period of tuber bulking. The combined effects will ultimately determine to what extent advancing the entire crop cycle is successful and to what extent this advance indeed contributes to the escape from late blight. Combining early planting with cultural practices which will make the environment more conducive for crop growth will make the result of earlier planting more reliable. In very specific situations, using transparent plastic sheets to cover the soil or the entire crop may be helpful. Ridging helps to advance early growth, and this positive effect can be enhanced by orienting the ridges properly or by planting the tubers in the south slope instead of the middle of the ridge (Bouws and Finckh 2008).

Finally advancing the entire crop cycle may also be achieved by pre-treatment of the seed tubers, e.g. by pre-sprouting. Early tuber yields can be achieved when seed tubers are planted which are properly pre-sprouted (Struik and Wiersema 1999; Struik 2007). Pre-sprouting can be defined as the initiation of sprout growth by exposing seed tubers to conditions favourable for sprouting before planting. This is probably the best way to advance the crop cycle as such treatments can be carried out in a rather controlled way with - if carried out by an experienced and knowledgeable farmer-predicted outcome and the desired impact.

Not all farmers like pre-sprouting and planting pre-sprouted tubers. It requires planning, extra labour, very careful planting whereas it might enhance certain diseases.

\section{Escape by Accelerating Canopy Growth}

Accelerating the build-up of the canopy growth, without necessarily changing the entire crop development is possible with agronomic practices such as extra 
nitrogen application (which might even delay tuber bulking a little). In this way, the overall resistance of the crop can be enhanced (see below), without losing yield potential. However, such treatments are less obvious than advancing tuber bulking. In years during which the late blight epidemic does not occur, or does occur but only very late in the season, this approach will result in higher yields than advancing the entire crop cycle. Effects of accelerating canopy growth on crop structure and therefore micro-environment within the crop need to be taken into account as well.

\section{Escape by Advancing Tuber Bulking}

Accelerating the crop development towards tuber bulking can be achieved by manipulating the physiological age of the seed tubers. The period between emergence and onset of tuber bulking is strongly affected by this seed characteristic (e.g., Van der Zaag and Van Loon 1987; Struik and Wiersema 1999; Struik et al. 2006). Early tuber yields can be achieved by planting seed tubers of an advanced physiological age, realized by storing them at relatively high temperatures or treating them with cold or heat shocks (e.g., Struik and Wiersema 1999). The strategy to use seed treatments as a tool to reduce late blight damage has been explored under organic farming conditions, together with other management options (TiemensHulscher et al. 2003; Hospers-Brands et al. 2005, Hospers-Brands et al. 2008). However, physiological age does not only affect onset of tuber bulking; it also influences emergence, early vigour, canopy structure, rate of tuber bulking, leaf senescence, etc. The overall impact needs to be evaluated and the outcome depends on the possible duration of the crop cycle.

Pre-sprouting and physiological age can be combined into an optimal seed pretreatment. After appearance, sprouts can even be removed (de-sprouting) which will hasten the ageing of the seed tubers and induce formation of new sprouts.

The positive effect of the escape by advancing tuber bulking might be partly offset by the simultaneously occurring increase in susceptibility to late blight as a consequence of the earlier maturity type created by the more advanced physiological age of the seed tuber. Although this effect has not yet been thoroughly proven, it is likely to occur to some extent. Crops with advanced tuber bulking caused by shortened photoperiods are also more susceptible to late blight (Colon, 1994; Colon et al. 1995).

The option of physiological age of the seed is promising. However, there is a strong interaction between cultivar and pre-treatment, and, therefore, each cultivar requires its own recipe and optimization.

\section{Escape by Accelerating Tuber Bulking Without Advancing It}

Chemical treatments of the foliage can accelerate tuber bulking once it has started. Such treatments can be used to make the crop earlier. However, the effects are often not well predictable and for most chemicals both negative and positive effects have been reported depending on the unpredictable environmental conditions. 


\section{Strengthening Foliage Resistance}

Race-non-specific resistance against late blight is strongly linked to the foliage maturity type (Visker et al. 2003a, b, 2004, 2005). Foliage maturity type is a complex syndrome of various features of the potato haulm, which includes at least termination of sympodial growth, sagging of plants, senescence of leaves, etc. Also in other crops, there are close associations between maturity type and resistance against diseases (e.g., Septoria resistance in wheat; Símon et al. 2004, Simon et al. 2005), but the mechanisms differ from physical to physiological and purely genetic. In potato the mechanisms of the associations between foliar maturity type and foliage resistance are partly genetic (with genes encoding for both characteristics closely linked on chromosome 5, Visker et al. 2003a, 2004, 2005) and partly physiological (Struik et al. 2005). It should be noted that the genetic variation in late blight resistance already expresses itself well before the variation in features contributing to the complex of foliage maturity is expressed.

Foliage maturity type has an effect on late blight resistance because it is associated with age-related factors of the entire plant and of the individual leaf (see section "age matters") and with leaf position effects, but also with aspects that might be associated with changes in leaf physiology as a result of the changes in physiology at whole plant level upon tuber initiation. The latter is suggested by the fact that foliage resistance in both early and late cultivars is sensitive to photoperiod: a long photoperiod results in a higher level of resistance (Colon 1994; Colon et al. 1995). In the potato plant, photoperiod also affects tuberization, flowering and dry matter partitioning to the tubers (e.g., Vreugdenhil and Struik 1989; Ewing and Struik 1992; Struik et al. 1999, 2005). A detailed analysis of the impact of foliage development on resistance level is therefore needed.

\section{Age Matters...}

The level of resistance to late blight is not constant during the development of the entire plant or of individual leaves. It is therefore relevant to take plant age and individual leaf age into account.

Plant age is a significant factor: in general older potato plants are slightly more resistant to late blight than younger plants. However, with a closer look at literature data, it seems that very young plants are susceptible, plants of intermediate age are most resistant, and old plants become more susceptible again (Visker 2005).

Also the age of the individual leaves is relevant. In general, literature suggests that older leaves are more susceptible, but this trend is very much intertwined with plant age effects and leaf position effects (Visker 2005).

\section{... But Leaf Position is More Important...}

Visker et al. (2003b) showed that the resistance of individual leaves remained the same throughout their life time. However, they also showed that there was a gradual increase in late blight resistance from basal leaves to apical leaves, suggesting that 
the position effect is more important than the leaf age effect. This was a very reproducible trend: it was consistently observed across experiments, cultivars, crops grown from different types of propagules, crops grown under contrasting conditions, across various detached leaf tests, etc.

The consistent effect of leaf position on radial lesion growth rate agrees with previous studies that describe a higher level of resistance for the more apical leaves (Hodgsom 1961; Mooi 1961; Carnegie and Colhoun 1980, 1982).

The mechanisms behind the increase of resistance with increasingly acropetal leaf positions are unknown. Unravelling these mechanisms could perhaps help in identifying new strategies for breeding for resistance against late blight, especially in early varieties.

\section{... Although Not for All Relevant Epidemiological Parameters}

The radial lesion growth rate measured on inoculated detached leaves taken from crops or plants is considered to be the best variable representing resistance to late blight in the field (Colon 1994; Colon et al. 1995). Spijkerboer (2004) at least proved that the variation among cultivars in lesion growth rate contributed most to differences in resistance among these cultivars. However, other parameters reflecting aspects of the fitness of $P$. infestans, are also relevant. These include infection probability, proportion of lesions that are sporulating, the latency period and the intensity of sporulation (Skelsey et al. 2005). The latter authors provided a formula for calculating the apparent rate of disease progress based on the entire set of fitness components. It is likely that not only the radial lesion growth rate but also the other parameters are affected by leaf position, although their response might differ. Unpublished research of the author and co-workers has shown that other infection parameters were indeed affected but in a much less consistent way and trends were not always clear cut. More research is needed in this respect.

\section{Physiology of the Leaf Position Effect}

Each leaf is more resistant than the preceding leaf on the same stem. This association between leaf position and susceptibility is the same for each cultivar investigated: each leaf on an earlier maturity type is more susceptible to late blight than the leaf at the corresponding position on a late maturing type. This also means that the association between late blight resistance and foliage maturity type is present throughout the entire plant and for each individual leaf (Visker 2005).

The reasons behind these consistent leaf position effects have not been revealed yet. Possible candidate mechanisms are related to the ontogenic development of the leaf as a function of the leaf position (including aspects such as anatomy, chemical structure, physical aspects of cell walls) (Visker 2005). It is also important to note that this leaf position effect occurred both in the absence and in the presence of tubers (Visker 2005).

One might be tempted to think that this leaf position effect is related to some kind of acquired resistance. Acquired resistance usually occurs because an older 
plant has experienced more stress and the more stress it has endured the more resistance it has acquired. But this does not make sense: acquired resistance is a characteristic at the level of the entire plant, not at the level of an individual organ (Visker 2005).

Another possible explanation might be associated with differences in hormonal profiles of the different leaf positions. Some results suggest that such profiles do exist and that they are related to level of tuber induction (see e.g., Struik et al. 1987), but more research is needed.

\section{Slowing Down the Initial Build-up of the Epidemic}

Leaf position is a dominant aspect of resistance against late blight. Late types are more resistant partly because they have more resistant leaves as they continue longer to produce new leaves. Does this phenomenon offer opportunities to change the crop in such a way that it becomes more resistant or at least that it can slow down the first phase of the epidemic? The leaf position effect suggests that advancing or accelerating canopy development might not be such a bad idea after all: with a more advanced development of leaves before the disease strikes, the crop will have more leaves at higher leaf positions, i.e. it will have more relatively resistant leaves. Similar effects could perhaps be realized by seed tuber treatments.

\section{Changing the Micro-environment}

A better proposition is most likely to create a canopy (using the options of seed tuber size, planting pattern, seed treatments etc.) that will allow a micro-environment which is not conducive to the infection process by the pathogen. The pathogen requires a certain period of leaf wetness and is very sensitive to direct sunlight. Basal leaves are therefore attacked earlier or more severely by late blight. Creating a more open canopy is an option, but will be associated with poorer radiation interception and lower radiation use efficiency, and thus a lower yield.

\section{Conclusion}

The physiological condition of the potato crop certainly plays a significant role in the development of the late blight epidemic, beyond factors determined by foliage maturity type and the genetic make-up of the crop. However, the size of the effect of the physiological condition is small compared with the devastating effect of the increase in aggressiveness of the oomycete. Moreover, manipulating that physiological condition in a predictable and effective way in order to reduce the susceptibility of the crop is difficult. This means that crop physiology can, as was the case for agronomy, only contribute little to combating the problem, certainly for early cultivars. Breeding for resistance remains our best option. 
Open Access This article is distributed under the terms of the Creative Commons Attribution Noncommercial License which permits any noncommercial use, distribution, and reproduction in any medium, provided the original author(s) and source are credited.

\section{References}

Bouws H, Finckh MR (2008) Effects of strip-intercropping of potatoes with non-hosts on late blight severity and tuber yield in organic production. Plant Pathol 57(5):916-927

Carnegie SF, Colhoun J (1980) Differential leaf susceptibility to Phytophthora infestans on potato plants of cv. King Edward. Phytopathol Z 98:108-117

Carnegie SF, Colhoun J (1982) Susceptibility of potato leaves to Phytophthora infestans in relation to plant age and leaf position. Phytopathol Z 104:157-167

Colon LT (1994) Resistance to Phytophthora infestans in Solanum tuberosum and wild Solanum species. $\mathrm{PhD}$ thesis, Wageningen Agricultural University, Wageningen. pp. 159

Colon LT, Turkensteen PW, Budding DJ, Hoogendoorn J (1995) Durable resistance to late blight (Phytophthora infestans) in old potato cultivars. Eur J Plant Pathol 101:387-397

Ewing EE, Struik PC (1992) Tuber formation in the potato: induction, initiation and growth. Hort Rev 14:89-198

Finckh MR, Schulte-Geldermann E, Bruns C (2006) Challenges to organic potato farming: disease and nutrient management. Potato Res 49:27-42

Finck MR, Wolfe MS, Lammerts van Bueren ET (2007) The Canon of Potato Science. 32. Variety mixtures and diversification strategies. Potato Res 50:335-339

Goverse A, Struik PC (2009) Debate on the exploitation of natural plant diversity to create late blight resistance in potato. Potato Res 52(3):265-271

Haverkort AJ, Struik PC, Visser RGF, Jacobsen E (2009) Applied biotechnology to combat late blight in potato caused by Phytophthora infestans. Potato Res 52(3):249-264

Hodgsom WA (1961) Laboratory testing of the potato for partial resistance to Phytophthora infestans. Am Potato J 38:259-264

Hospers-Brands AJTM, Struik PC, Tiemens-Hulscher M, Putten PEL van der, Jansen E (2005) Effects of physiological age of seed tubers on tuber yield and the susceptibility of the potato crop to late blight (Phytophthora infestans) in organic agriculture. Proceedings 16th Triennial Conference of the EAPR, July 17-22, 2005, Bilbao, Spain. pp. 432-436

Hospers-Brands M, Timmermans B, van der Putten P, Struik P, Tiemens-Hulscher M, Lammerts van Bueren E (2008) Late blight in organic potato growing managing resistance and early tuber growth. In: Neuhoff D, Halberg N, Alfldi T, Lockeretz W, Thommen A, Rasmussen IA, Hermansen J, Vaarst M, Lck L, Carporali F, Jensen HH, Migliorini P, Willer H (ed) Cultivating the Future Based on Science. Proceedings of the Second Scientific Conference of the International Society of Organic Agriculture Research (ISOFAR), held at the 16th IFOAM Organic World Congress in Cooperation with the International Federation of Organic Agriculture Movements (IFOAM) and the Consorzio ModenaBio, Modena, Italy, 18-20 June 2008, Int Soc Org Agric Res (ISOFAR), c/o IOL, DE-Bonn, Research Institute of Organic Agriculture FiBL, CH-Frick. Available at: http://orgprints.org/13672 and http://orgprints.org/13674. Accessed: 20 Aug 2010

Lammerts van Bueren ET, Tiemens-Hulscher M, Struik PC (2008) Cisgenesis does not solve the late blight problem of organic potato production: alternative breeding strategies. Potato Res 51:89-99

Mooi JC (1961) Experiments on testing field resistance to Phytophthora infestans by inoculating cut leaves of potato varieties. Eur Potato J 8:182-183

Phillips SL, Shaw MW, Wolfe MS (2005) The effect of potato variety mixtures on epidemics of late blight in relation to plot size and level of resistance. Ann Appl Biol 147:245-252

Pilet F, Chacón G, Forbes GA, Andrivon D (2006) Protection of susceptible potato cultivars against late blight in mixtures increases with decreasing disease pressure. Phytopathology 96:777-783

Símon MR, Worland AJ, Struik PC (2004) Influence of plant height and heading date on the expression of the resistance to Septoria tritici blotch in near isogenic lines of wheat. Crop Sci 44:2078-2085

Simon MR, Perello AE, Cordo CA, Larran S, van der Putten PEL, Struik PC (2005) Genetic variation in resistance to septoria tritici blotch (Mycosphaerella graminicola) and its association with genetic variation in plant height and heading date in Argentinean wheat cultivars. Agron J 97:1072-1081

Skelsey P, Rossing WAH, Kessel GJT, Powell J, van der Werf W (2005) Influence of host diversity on development of epidemics: an evaluation and elaboration of mixture theory. Phytopathology 95:328-338 
Spijkerboer HP (2004) From lesion to region: epidemiology and management of potato late blight. Ph.D. thesis, Wageningen University, Wageningen

Struik PC (2006) Trends in agricultural science with special reference to research and development in the potato sector. Potato Res 49:5-18

Struik PC (2007) The canon of potato science: 40. Physiological age of seed tubers. Potato Res 50:375377

Struik PC, Wiersema SG (1999) Seed potato technology. Wageningen Pers, Wageningen

Struik PC, Boon EJ, Vreugdenhil D (1987) Effects of extracellular extracts from leaves on the tuberization of cuttings of potato (Solanum tuberosum L.). Plant Physiol 84:214-217

Struik PC, Vreugdenhil D, van Eck HJ, Bachem CW, Visser RGF (1999) Physiological and genetic control of tuber formation. Potato Res 42:313-331

Struik PC, Visker MHPW, Pauwels JP, Colon LT (2005) Are cuttings suitable for assessing maturity type in potato (Solanum tuberosum)? Ann Appl Biol 147:27-34

Struik PC, van der Putten PEL, Caldiz DO, Scholte K (2006) Response of stored potato seed tubers from contrasting cultivars to accumulated day-degrees. Crop Sci 46:1156-1168

Tiemens-Hulscher M, Colon LT, Flier WG, Kessel GJT, Budding DJ, ter Berg C, Burgt GJ van der, Hospers M, Lammerts van Bueren ET (2003) Naar beheersingsstrategieën voor Phytophthora infestans in de biologische aardappelteelt. Louis Bolk Instituut, Driebergen, Nederland, Plant Research International, Wageningen, Nederland. pp. 118

Tiemens-Hulscher M, Lammerts van Bueren ER, Hospers-Brands AJTM, Timmermans BGM, van der Putten PEL, Struik PC (2007) Blijft biologische aardappelteelt in Nederland mogelijk? Gewasbescherming 35:246-250

Van der Zaag DE, Van Loon CD (1987) Effect of physiological age on growth vigour of seed potatoes of two cultivars. 5. Literature review and integration of some experimental results. Potato Res 30:451472

Visker MHPW (2005) Association between late blight resistance and foliage maturity type in potato. Physiological and genetic studies. Doctorate thesis, Wageningen University, The Netherlands. pp. 160

Visker MHPW, Keizer LCP, van Eck HJ, Jacobsen E, Colon LT, Struik PC (2003a) Can the QTL for late blight resistance on potato chromosome 5 be attributed to foliage maturity type? Theor Appl Gen 106:317-325

Visker MHPW, Keizer LCP, Budding DJ, van Loon LC, Colon LT, Struik PC (2003b) Leaf position prevails over plant age and leaf age in reflecting resistance to late blight in potato. Phytopathology 93:666-674

Visker MHPW, van Raaij HMG, Keizer LCP, Struik PC, Colon LT (2004) Correlation between late blight resistance and foliage maturity type in potato. Euphytica 137:311-323

Visker MHPW, Heilersig HJB, Kodde LP, van de Weg WE, Voorrips RE, Struik PC, Colon LT (2005) Genetic linkage of QTLs for late blight resistance and foliage maturity type in six related potato progenies. Euphytica 143:189-199

Vreugdenhil D, Struik PC (1989) An integrated view of the hormonal regulation of the tuber formation in potato (Solanum tuberosum L.). Physiol Plant 75:525-531 